\title{
Antarctic krill swarm characteristics in the Southeast Atlantic sector of the Southern Ocean
}

\author{
Bjørn A. Krafft ${ }^{1, * * * *}$, Georg Skaret ${ }^{1, * *}$, Tor Knutsen ${ }^{1}$, Webjørn Melle ${ }^{1}$, Thor Klevjer ${ }^{2,3}$, \\ Henrik Søiland ${ }^{1}$
}

\author{
${ }^{1}$ Institute of Marine Research, 5870 Bergen, Norway \\ ${ }^{2}$ Department of Biology, University of Oslo, 0316 Oslo, Norway \\ ${ }^{3}$ King Abdullah University of Science and Technology, Thuwal 23955-6900, Saudi Arabia
}

\begin{abstract}
Knowledge about swarm dynamics and underlying causes is essential to understand the ecology and distribution of Antarctic krill Euphausia superba. We collected acoustic data and key environmental data continuously across extensive gradients in the little-studied Southeast Atlantic sector of the Southern Ocean. A total of 4791 krill swarms with swarm descriptors including swarm height and length, packing density, swimming depth and inter-swarm distance were extracted. Through multivariate statistics, swarms were categorized into 4 groups. Group 2 swarms were largest (median length $108 \mathrm{~m}$ and thickness $18 \mathrm{~m}$ ), whereas swarms in both Groups 1 and 4 were on average small, but differed markedly in depth distribution (median: $52 \mathrm{~m}$ for Group 1 vs. $133 \mathrm{~m}$ for Group 4). There was a strong spatial autocorrelation in the occurrence of swarms, and an autologistic regression model found no prediction of swarm occurrence from environmental variables for any of the Groups 1, 2 or 4. Probability of occurrence of Group 3 swarms, however, increased with increasing depth and temperature. Group 3 was the most distinctive swarm group with an order of magnitude higher packing density (median: 226 ind. $\mathrm{m}^{-3}$ ) than swarms from any of the other groups and about twice the distance to nearest neighbor swarm (median: $493 \mathrm{~m}$ ). The majority of the krill were present in Group 3 swarms, and the absence of association with hydrographic or topographic concentrating mechanisms strongly suggests that these swarms aggregate through their own locomotion, possibly associated with migration.
\end{abstract}

KEY WORDS: Euphausia superba $\cdot$ Aggregation $\cdot$ Acoustics $\cdot$ Swarm $\cdot$ Bouvetøya

\section{INTRODUCTION}

There is increasing evidence that many marine invertebrates are aggregative due to self-propelled locomotion and social attraction, rather than being drifting passive patches (Ritz 1994). The adaptation of such gregarious behavior in marine invertebrates has been related to several factors including hydrodynamic and energetic advantages (Ritz 2000, Ritz et al. 2001), improved foraging (Ritz 1994), predator avoidance (Hamner et al. 1983, O'Brien \& Ritz 1988, Evans et al. 2007) and reproductive facilitation (Ritz 2000).
Antarctic krill Euphausia superba is recognized as one of the most pronounced aggregative marine invertebrates, spending large parts of its life cycle in swarms (Marr 1962, Hamner \& Hamner 2000, Ritz 2000). Studies at the swarm level are thus highly relevant for understanding the behavioral ecology of $E$. superba. Increased understanding of swarm properties and relationship with the environment is also important for predicting krill distribution at various scales. Such information is directly usable for understanding distribution and behavior of the many predators dependent on krill and for informing the fisheries. 
Determining the causal mechanisms underlying swarm behavior is a challenge, since the properties of Euphausia superba swarms are likely to be affected by a combination of responses to external and internal factors including the ambient environment, influence from neighbor individuals and internal state factors such as maturity. However, progress has been made, in particular due to the use of acoustic methods, which provide large observation volumes as well as high temporal and spatial resolution (e.g. Ricketts et al. 1992, Zhou \& Dorland 2004, Tarling et al. 2009, Cox et al. 2010).

A few acoustic studies have focused on internal factors underlying swarm properties. Ricketts et al. (1992) found no relation between swarm properties and biological characteristics of krill at a small scale. When investigating such relationships at a mesoscale, Tarling et al. (2009) found that swarms were generally larger with higher packing density when the individuals were immature and of small size. Among the studies focusing on external factors underlying swarm properties, several have found that size and packing density of swarms differ between day and night (Ricketts et al. 1992, Sprong \& Schalk 1992, Zhou \& Dorland 2004). Lascara et al. (1999) reported variations in swarm properties related to season, and Tarling et al. (2009) found that surface fluorescence and light level influenced swarm properties at meso-scale, suggesting that feeding conditions modify swarm properties. Euphausia superba swarm properties have also been shown to change according to the bathymetry (Lascara et al. 1999, Klevjer et al. 2010, Cox et al. 2011), with the largest and most densely packed swarms occurring in shelf regions. Klevjer et al. (2010) explained this behavior as a predator avoidance response. Cox et al. (2009) found indications that swarms were influenced and shaped by predators at a small scale, and Brierley \& Cox (2010) modeled realistic krill swarm morphologies as emerging from individuals avoiding predation while maintaining sufficient access to oxygen.

Euphausia superba has a vast oceanic circumpolar distribution (Marr 1962), and swarm properties differ between areas (Miller et al. 1993). In the present study, we investigate E. superba swarms recorded acoustically during a survey covering broad eastwest and north-south gradients in the little-studied Southeast Atlantic sector of the Southern Ocean. The survey integrates areas with different environmental properties including frontal zones, areas at the northern outskirts of the distribution area for E. superba and southern areas close to the ice edge. The aim of the study was first to determine whether E. superba swarms could be robustly grouped according to similarities in swarm morphology, vertical positioning and nearest neighbor distance reflecting different behaviours. If swarm groups could be defined, we secondly aimed to determine whether there was a relationship between swarm properties and environmental key variables which were measured continuously. Current speed was of particular interest since it is very important for krill transportation (Huntley \& Niiler 1995, Thorpe et al. 2007), but has been little studied in relation to swarm properties.

\section{MATERIALS AND METHODS}

\section{Survey platform and area}

Transect data were collected with the Norwegian RV 'G. O. Sars' as part of the Antarctic Krill and Ecosystem Studies (AKES) project in 2008. Two cruise legs were carried out (Fig. 1), the first starting on 4 January in Montevideo, arriving at South Georgia $\left(54^{\circ} \mathrm{S}, 36^{\circ} \mathrm{W}\right)$ for calibration and finescale studies on 9 January. Data collection for the present study from the first leg started on 22 January when the vessel headed towards Bouvetøya $\left(54^{\circ} \mathrm{S}, 3^{\circ} \mathrm{E}\right)$ and ended on 7 February when the vessel steamed north of $50^{\circ} \mathrm{S}$. The second leg of the survey followed the $\sim 15^{\circ} \mathrm{E}$ meridian southwards and data collection for the present study started when the vessel crossed $50^{\circ} \mathrm{S}$ on 24 February before heading further south to $67^{\circ} 07^{\prime} \mathrm{S}$. The vessel then turned northwards following the $\sim 5^{\circ} \mathrm{E}$ meridian and data collection ended 15 March.

\section{Biological data sampling}

Samples of Euphausia superba were acquired at 40 trawl stations (Fig. 1) using a 'macroplankton trawl' with a $38 \mathrm{~m}^{2}$ mouth opening and a mesh size of $3 \mathrm{~mm}$ from the trawl-opening to the rear end, and a 'micronekton trawl', with a vertical opening of $14 \mathrm{~m}$ and variable mesh sizes in the front part of the trawl, but $6 \mathrm{~mm}$ stretched meshes in the rear section. Samples with the macroplankton trawl were obtained from standardized depths from 750 to $0 \mathrm{~m}$ during a haul. With the micronekton trawl, targeted sampling depths ranged from $765 \mathrm{~m}$ to surface waters, but the average maximum depth was $\sim 150 \mathrm{~m}$ (see also Krafft et al. 2010 for further details). E. superba body length was measured ( $\pm 1 \mathrm{~mm}$ ) for 6609 animals from the anterior margin 
of the eye to tip of telson (AT length) excluding the setae, according to the 'Discovery method' (Mauchline 1980). In order to resolve any spatial distribution of the krill length from the large study area, a hierarchical cluster analysis was carried out. The length distributions from the different clusters were later used in the acoustic analysis for target strength (TS) estimations. The clustering analysis was based on a similarity matrix derived from Euclidean distances, following methods described in Siegel et al. (2004). Data from all stations sampled during the survey with a minimum of 20 measured specimens, were included in the cluster analysis. During 18 to 22 January, shortly prior to the onset of the survey for the present study, 10 trawls, with krill samples obtained in 7 of them, were carried out within a small area during acoustic case studies east of South Georgia (Fig. 2). These stations were not included in the length clustering analysis, but krill length distribution from the 7 stations combined were included to represent the South Georgia area for the TS estimation (Figs. $2 \& 3$ ).

\section{Acoustic data acquisition}

Samples of acoustic mean volume backscattering strength $\left(\mathrm{S}_{\mathrm{v} i} \mathrm{~dB}\right.$ re $1 \mathrm{~m}^{-1}$ ) were collected at 10 knots vessel speed with a Simrad EK60 echo sounder with transducers mounted on a retractable keel. The echo sounder can be operated at 6 frequencies (18, $38,70,120,200$ and $333 \mathrm{kHz}$ ), but only data from the 38 and $120 \mathrm{kHz}$ frequencies were included in our analysis. The transducer specifications and settings are given in Table 1. Data were logged down to $350 \mathrm{~m}$ depth, below which depth the attenuation at $120 \mathrm{kHz}$ was considered to be too high for the data to be useful. The echo sounder system was calibrated in Strømness Bay, South Georgia prior to the survey according to standard methods (Foote et al. 1987).

\section{Acoustic data processing and analyses}

The acquired acoustic data were processed with the Large Scale Survey System (Korneliussen et al. 2006). The data were corrected for system delay, transducer

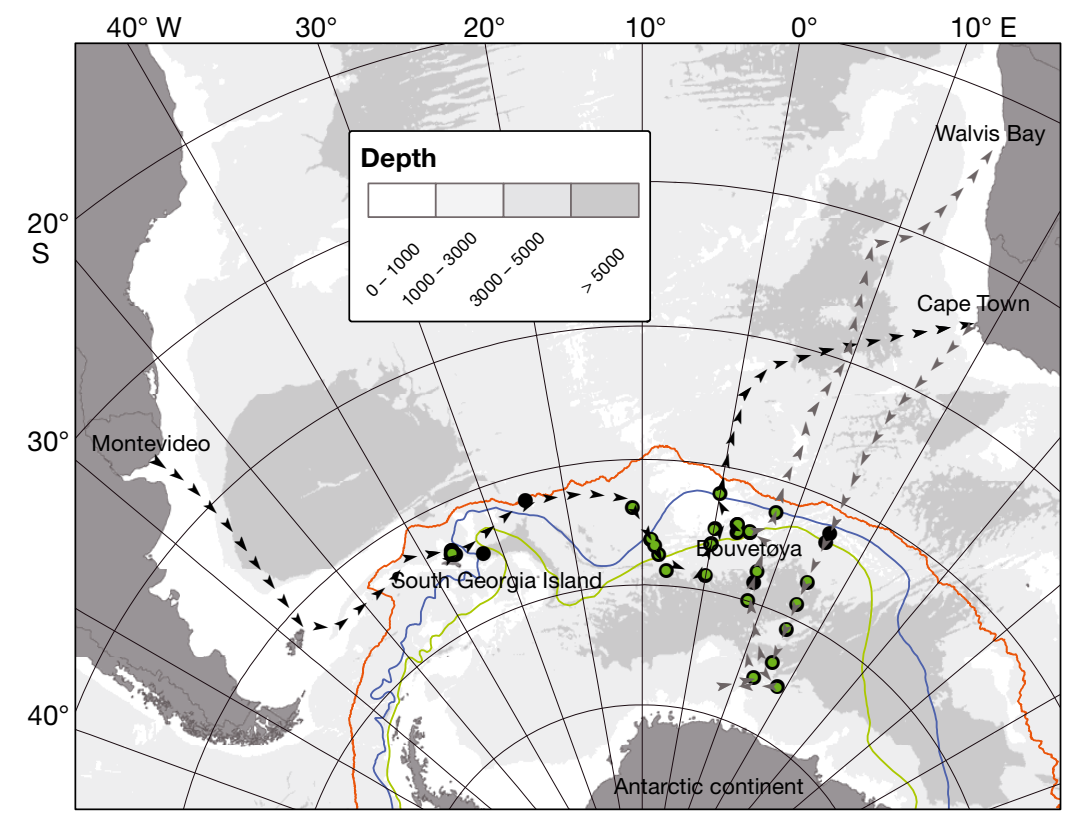

Fig. 1. Survey track during Antarctic Krill and Ecosystem Studies cruise, carried out in 2 parts (arrow heads: black $=\operatorname{leg} 1$, grey $=\operatorname{leg} 2$ ) from 4 January to 28 March 2008. - trawl stations with catch of Euphausia superba; : stations with environmental data included in this study. Lines: red = Antarctic Polar Front; blue: South Antarctic Circumpolar Current Front; green: South Boundary Front (Orsi et al. 1995)

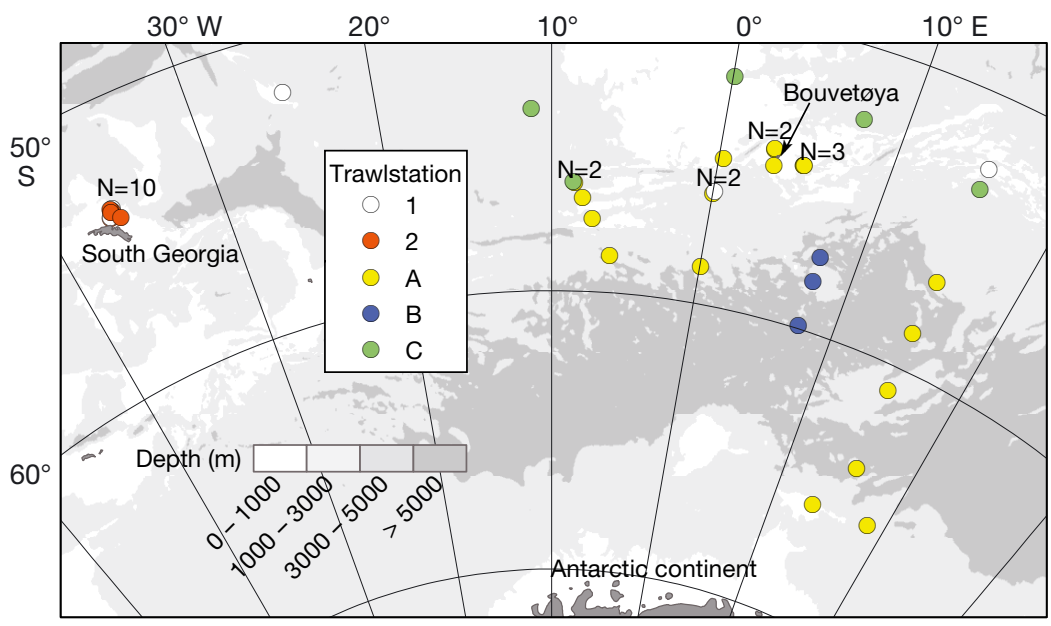

Fig. 2. Euphausia superba length cluster groups resulting from hierarchical cluster analysis. Groups A, B and C denote the 3 identified length cluster groups (see Table 2). Stations denoted ' 1 ' were not included in the cluster analysis due to few samples ( $<20$ individuals), and stations denoted ' 2 ' were sampled at South Georgia prior to the survey and not included in the cluster analysis, but included in the estimation of krill target strength (see 'Materials and methods: Biological data sampling'). Where 2 or more trawls were carried out in close proximity, $\mathrm{N}=$ number of trawls 

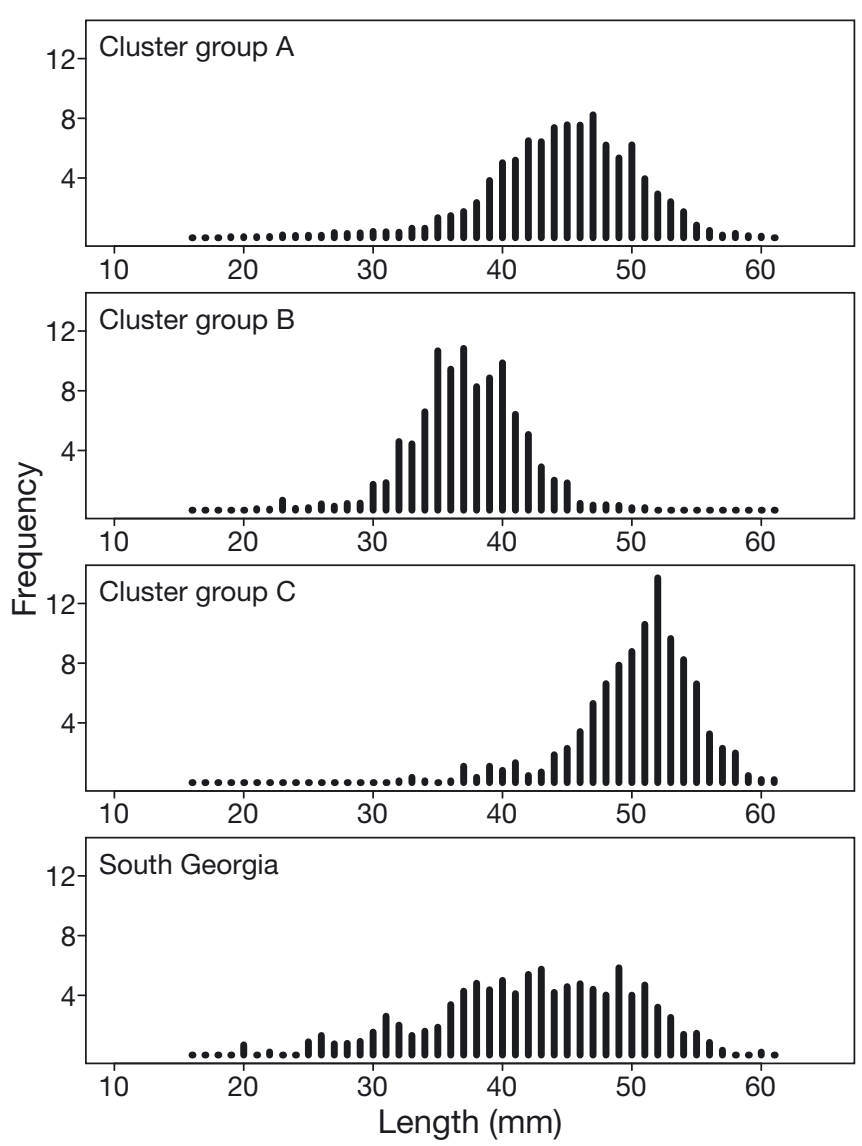

Fig. 3. Distribution of krill body lengths for the different cluster groups and the South Georgia region.

Table 1. Specifications and settings for the 38 and $120 \mathrm{kHz}$ transducers

\begin{tabular}{|c|c|c|}
\hline Echo sounder specification & $38 \mathrm{kHz}$ & $120 \mathrm{kHz}$ \\
\hline Transducer type & ES38B & ES120-7C \\
\hline Transducer depth (m) & 8.6 & 8.6 \\
\hline Transmitted power (W) & 2000 & 250 \\
\hline Pulse duration (ms) & 1.024 & 1.024 \\
\hline Pulse repetition frequency $(\mathrm{Hz})$ & $1^{\mathrm{a}}$ & $1^{\mathrm{a}}$ \\
\hline Absorption coefficient $\left(\mathrm{dB} \mathrm{km} \mathrm{km}^{-1}\right)$ & 10 & 26.6 \\
\hline Sound speed $\left(\mathrm{ms}^{-1}\right)$ & 1456.6 & 1456.6 \\
\hline Sample interval (m) & 0.186 & 0.186 \\
\hline Two-way beam angle (dB) & -20.8 & -21 \\
\hline $\mathrm{S}_{\mathrm{v}}$ transducer gain $(\mathrm{dB})$ & 25.75 & 26.9 \\
\hline $\mathrm{S}_{\mathrm{a}}$ correction $(\mathrm{dB})$ & -0.67 & -0.28 \\
\hline Angle sensitivity alongship & 21.9 & 23 \\
\hline Angle sensitivity athwartship & 21.9 & 23 \\
\hline $\begin{array}{l}3 \mathrm{~dB} \text { nominal beamwidth } \\
\text { alongship }\left({ }^{\circ}\right)\end{array}$ & 6.98 & 6.4 \\
\hline Angle off alongship $\left({ }^{\circ}\right)$ & -0.17 & -0.19 \\
\hline $\begin{array}{l}3 \mathrm{~dB} \text { nominal beamwidth } \\
\text { athwartship }\left({ }^{\circ}\right)\end{array}$ & 7.03 & 6.54 \\
\hline Angle off athwartship $\left(^{\circ}\right)$ & -0.06 & 0.01 \\
\hline
\end{tabular}

position and estimated noise and smoothed, according to the first 8 steps in the 12-step procedure for echo sounder data processing described in Korneliussen et al. (2009). The data were imported into Echoview version 4.30 where the swarm detection was carried out. Swarm detection was done on the $120 \mathrm{kHz}$ echogram using a threshold of $-70 \mathrm{~dB}$, which was proposed by Lawson et al. (2008) based on the theoretical threshold backscattering strength of swarming adult Euphausia superba assuming equidistance between individuals at their assumed maximum visual range of $1 \mathrm{~m}$. The SHAPES algorithm in Echoview was applied to extract regions from the echogram corresponding to swarms, with detection settings applied according to Tarling et al. (2009). These SHAPES detection settings were demonstrated by Tarling et al. (2009) to be relatively robust to changes and were considered appropriate for our purpose since the acoustic sample resolution was similar to the one used in their study. Minimum length and height of the detected regions were hence set to 15 and $2 \mathrm{~m}$, minimum candidate length and height to 10 and $1 \mathrm{~m}$, and horizontal and vertical linking distances to 15 and $5 \mathrm{~m}$, respectively.

In order to identify and extract recordings of Euphausia superba swarms from the detected regions, the relative acoustic backscatter of a region recorded at 120 and $38 \mathrm{kHz}$ was used. A region was defined as E. superba and extracted if the $\Delta \mathrm{S}_{\mathrm{v} 120-38}$ fell within a specified window (e.g. Watkins \& Brierley 2002, Lawson et al. 2008). The boundaries of the windows were predicted for each length distribution cluster (see previous section) according to minimum and maximum estimated $\Delta \mathrm{S}_{\mathrm{v} 120-38}$ for krill from the body length distribution of the given length distribution clusters. The $2.5 \%$ lowest and $2.5 \%$ highest length values were omitted for the prediction. The $\Delta \mathrm{S}_{\mathrm{v} 120-38}$ windows corresponding to the different length distribution clusters can be found in Table 2 .

Table 2. Key parameter values for the different krill length cluster groups: Target strength weighted according to Euphausia superba body length distribution, length range $(2.5 \%$ lowest and $2.5 \%$ highest recordings omitted) and lower and upper boundaries of backscatter volume for the 38 and $120 \mathrm{kHz}$ transducers $\left(\mathrm{S}_{\mathrm{v} 120-38}\right)$ for including acoustic echogram regions as krill targets. SG: South Georgia group (not included in the hierarchical clustering analysis)

\begin{tabular}{|lccc}
\hline $\begin{array}{l}\text { Cluster } \\
\text { group }\end{array}$ & $\begin{array}{c}\text { Weighted target } \\
\text { strength }(\mathrm{dB})\end{array}$ & $\begin{array}{c}\text { Length } \\
\text { range }(\mathrm{mm})\end{array}$ & Range $\mathrm{S}_{\mathrm{v} 120-38}$ \\
\hline A & -74.23 & $31-53$ & $2.28-13.01$ \\
B & -75.63 & $29-44$ & $5.33-16.68$ \\
C & -73.27 & $39-57$ & $2.28-13.01$ \\
SG & -74.74 & $26-54$ & $2.28-16.68$ \\
\hline
\end{tabular}


For the prediction of the boundaries of the $\Delta \mathrm{S}_{\mathrm{v} 120-38}$ windows to be used for krill identification and also for the estimation of swarm packing density, we applied the stochastic distorted wave-borne approximation (SDWBA)-model which is a representation of the krill body and reflection properties by a sequence of cylinders (Demer \& Conti 2003). We applied the SDWBA-implementation as described in Calise \& Skaret (2011). This is a corrected version of the Conti \& Demer (2006) implementation, and is adopted by CCAMLR (CCAMLR 2010). The model was run for standard Euphausia superba AT length of $38.35 \mathrm{~mm}$ (McGehee et al. 1998), E. superba swimming orientation set to $0^{\circ}\left(\mathrm{SD} 27^{\circ}\right.$ ) (Lawson et al. 2006), fatness coefficient set to $20 \%$, and values of density and sound speed contrasts according to Foote et al. (1990). From a full model run with the given settings, coefficients to run a simplified model version were extracted. The simplified version is computationally more efficient at the cost of a modest increase in uncertainty, and is practical for use when estimating TS over whole distributions of lengths (Conti \& Demer 2006). The simplified SDWBA was used to calculate the lower and upper boundaries of the $\Delta \mathrm{S}_{\mathrm{v} 120-38}$ windows for each length distribution cluster (Table 2). The lowest length value was rounded down and the highest rounded up to the closest 10 $\mathrm{mm}$ value according to the CCAMLR-protocol (CCAMLR 2010). Finally, krill TS for estimation of swarm packing density was estimated for each $1 \mathrm{~mm}$ length bin contained in the krill length distributions, and a TS weighted according to the length frequency distribution was estimated for each length distribution cluster.

\section{Acquisition of environmental data}

A $75 \mathrm{kHz}$ RDI Ocean Surveyor ADCP (acoustic doppler current profiler) continuously measured current velocities and direction. It was run in narrow band mode with 60 vertical bins each $16 \mathrm{~m}$ long and data were obtained down to 750 to $800 \mathrm{~m}$ using a blanking length of $16 \mathrm{~m}$ of no data acquisition. The ADCP was synchronized with the hull mounted EK60 echosounder systems to avoid acoustic interference, and the ping rate was about one ping each $3 \mathrm{~s}$. The navigation data was obtained from the ship's SeaPath navigation system. The RDI software VmDas was used for data acquisition rendering 5-min ensembles or a horizontal resolution of $\sim 1.5 \mathrm{~km}$ (at 10 knot vessel speed). The output from the VmDas were postprocessed using the CODAS system (CODAS soft- ware is available from the 'Currents' group at the University of Hawaii, SOEST: http://currents.soest. hawaii.edu), in which the processed ADCP data were run through a 3 point median filter to remove outliers. The $75 \mathrm{kHz}$ ADCP is mounted in a drop keel separate from the drop keel of the echo sounder transducers and applied at $6.5 \mathrm{~m}$ depth. The first measured depth bin (24 to $40 \mathrm{~m}$ ) is often contaminated in bad weather due to bubble noise and thus in order to reduce noise to a minimum we used averaged velocity in the depth range 56 to $112 \mathrm{~m}$. In the southernmost part of the survey area the ADCP was switched off for a period to avoid interference with acoustic bottom mapping, and there were also some additional smaller gaps in the data due to technical problems.

Temperature and salinity were recorded along the cruise track using a ship-mounted thermosalinograph (SBE21) with a SBE 38 thermometer mounted close to the water intake on the drop keel. The water intake for the thermosalinograph was located approximately $8 \mathrm{~m}$ below the sea surface. Comparing the salinity data from the thermosalinograph with the Seabird 911CTD data, employed at predetermined positions along the track, showed a minor offset of -0.025 , and this factor was used for correction. There were also some minor gaps in the salinity data due to problems with small objects periodically entangled in the salinity cell. These data were removed. To remove spikes in the data, a sliding median filter was used which resulted in a time resolution of about 1 min, or with 10 knots vessel speed about $0.3 \mathrm{~km}$ horizontal resolution.

Light was measured from the ship's light sensor, a PAR LITE (Kipp \& Zonen; www.kippzonen.com) connected to a Vaisala MILOS 520 Weather station. Light measurements obtained from the weather station were 10-min averaged PAR (photosynthetically active radiation) in $\mu \mathrm{mol}$ (photons) $\mathrm{m}^{-2} \mathrm{~s}^{-1}$. Bottom depth data was extracted from the General Bathymetric Chart of the Oceans (GEBCO: www.gebco.net).

\section{Multivariate data analysis}

As input variables for the multivariate data analyses, swarm characteristics from a total of 4791 echo sounder recordings retained as Euphausia superba swarms were included. The swarm characteristics calculated in Echoview included (1) horizontal swarm length (m), (2) vertical swarm extension ('thickness') (m), (3) swarm depth (m) measured as distance from the surface to the centre of a swarm, (4) minimum 
inter-swarm distance $(\mathrm{m})$ calculated from the centre of a given swarm to the centre of the closest neighbor swarm, and (5) packing density of a swarm $\left(\mathrm{N}_{\mathrm{v}}\right.$, ind. $\mathrm{m}^{-3}$ ) calculated as $\mathrm{N}_{\mathrm{v}}=10^{(\mathrm{Sv}-\mathrm{TS}) / 10}$, where $\mathrm{S}_{\mathrm{v}}$ is the mean volume backscatter of a swarm $\left(\mathrm{dB}\right.$ re $\left.1 \mathrm{~m}^{-1}\right)$ and TS was set according to the different length distribution clusters (Table 2). In addition to the 5 input variables, an abundance related swarm descriptor adopted from Tarling et al. (2009) as sum abundance $\left(\mathrm{N}_{\mathrm{t}}\right.$, ind. $\mathrm{m}^{-1}$ ) was calculated but not included in the analysis since the values depend directly on the values of other included swarm descriptors. Sum abundance was calculated as $\mathrm{N}_{\mathrm{t}}=\mathrm{N}_{\mathrm{v}} A$, where $A$ is swarm area as a vertical cross section as displayed on the echogram. This measure provides a relevant approach to quantifying abundance of E. superba in swarms without making inferences about 3D shape.

The set of 5 parameters of swarm properties were $\log _{10}(x+1)$ transformed to reduce the influence of extreme values, standardized and introduced into a principal component analysis (PCA) (Zar 1996). From the PCA results 3 new uncorrelated principal components (PCs; Table 3) had sufficient explanatory power to be retained by using the latent root criterion (Hair et al. 1998, Norman \& Streiner 2008). The scores from these 3 PCs were used as input for a $K$-means cluster analysis in order to objectively group sets of observations with similar properties (Hartigan \& Wong 1979). An assessment of appropriate clustering partitioning was done using the Calinski-Harabasz criterion (Calinski \& Harabasz 1974). The criterion is based on the $F$ statistic index $\left[\mathrm{SS}_{\mathrm{B}} /(K-1)\right] /\left[\mathrm{SS}_{\mathrm{W}} /(\mathrm{n}-K)\right]$, where $\mathrm{n}$ is the number of data points, $K$ is the number of clusters, $\mathrm{SS}_{\mathrm{W}}$ is the sum of squares within the clusters and $\mathrm{SS}_{\mathrm{B}}$ is the sum of squares among the clusters. A range from 2 to 10 groups was assessed, and partition into 4 swarm groups provided the highest index value (Table 4). In order to investigate the robustness of the multivariate analysis, 1000 observations with attributed swarm descriptors were selected at random from the data material and the PCA and $K$-means clustering were conducted on the new data set. This procedure for testing robustness was repeated 3 times.

In order to investigate for potential spatial autocorrelation in the occurrence of swarm types, estimates of the autocorrelation function were computed and plotted using the 'acf' function in $\mathrm{R}$ which is based on the definitions given in Venables \& Ripley (2002). The first ca. $1000 \mathrm{~km}$ of the survey was considered appropriate for the assessment of autocorrelation since swarms from all 4 cluster groups were detected in high numbers here. The number of swarms of a given swarm cluster group per $\mathrm{km}$ distance was used as input, and the analysis was done separately for the 4 swarm groups. The autocorrelation estimates and corresponding distance lags were used further when linking swarm properties and environmental variables described in the next section. In addition, for making inferences about swarm cluster group differences in each of the swarm properties length, thickness, depth, inter-swarm distance and packing density, an exponential

Table 4. Data derived from the 38 and $120 \mathrm{kHz}$ frequencies using the Simrad EK60 echosounder with the properies of the 4 distinguished swarm groups. Median, 1st and 3rd quartiles are shown. $\mathrm{n}=$ number of swarms

\begin{tabular}{|c|c|c|c|c|c|c|c|c|c|c|c|c|}
\hline \multirow[t]{2}{*}{ Swarm descriptor } & \multicolumn{3}{|c|}{ Group $1(\mathrm{n}=1771)$} & \multicolumn{3}{|c|}{ Group $2(\mathrm{n}=836)$} & \multicolumn{3}{|c|}{ Group $3(n=1468)$} & \multicolumn{3}{|c|}{ Group $4(\mathrm{n}=716)$} \\
\hline & $1 \mathrm{st}$ & Median & $3 r d$ & 1st & Median & 3rd & $1 \mathrm{st}$ & Median & 3rd & $1 \mathrm{st}$ & Median & $3 r d$ \\
\hline Length (m) & 24 & 30 & 39 & 74 & 108 & 180 & 32 & 40 & 54 & 24 & 30 & 39 \\
\hline Thickness (m) & 3 & 4 & 6 & 13 & 18 & 27 & 6 & 9 & 13 & 3 & 5 & 7 \\
\hline Swarm depth (m) & 42 & 52 & 62 & 46 & 57 & 73 & 40 & 52 & 65 & 90 & 113 & 155 \\
\hline Inter-swarm distance (m) & 44 & 76 & 143 & 63 & 104 & 200 & 235 & 493 & 1088 & 137 & 296 & 717 \\
\hline Packing density (ind. $\mathrm{m}^{-3}$ ) & 6 & 11 & 30 & 10 & 27 & 91 & 115 & 226 & 446 & 11 & 28 & 75 \\
\hline Sum abundance & 352 & 853 & 2876 & 6265 & 24918 & 107314 & 21005 & 56525 & 141689 & 703 & 2432 & 9514 \\
\hline
\end{tabular}


curve was fitted to experimental variograms for each of the properties. This was done using an ordinary least square method, and the curve parameters were used to assess the range or distance required for samples to be considered independent with regards to the swarm property under scrutiny.

\section{Analyzing explanatory variables}

In order to explore the presence of a relationship between swarms and environment variables, we compared the influence of environmental variables on the occurrence of particular swarm cluster groups. Environmental variables (current speed and direction, temperature, salinity, light level and bottom depth $b$; see 'Acquisition of environmental data') that had b collected continuously including were investigated as predictors for the presence of swarms belonging to a particular swarm cluster group. The resolution of the environmental data were $\sim 1.5 \mathrm{~km}$ for the current data, $\sim 3 \mathrm{~km}$ for light data and $\sim 0.3 \mathrm{~km}$ for the temperature and salinity data. All periods with gaps in any of the environmental data were removed, resulting in the retention of 2745 swarms.

A binomial logistic regression model was applied to the data-set using the $\mathrm{R}$ software (Croissant 2011). The model is used to analyze potential relationships between a binary response variable and metric or dichotomous independent variables. In our case, the model was used to predict the presence (1) or absence (0) of a given swarm cluster group, with the environmental variables used as predictors. Predictions for each swarm cluster group were made separately.

In the binomial logistic regression model, a binary distribution of the response variable is assumed, and the probabilities of an event occurring or not can be denoted $P$ and $1-P$, respectively. Since the response is a proportion, we use a logistic transformation of the form $\operatorname{Logit}(P)=\log (P / 1-P)$ to link the dependent to the explanatory variables. For $p$ explanatory variables $x_{1}, x_{2} \ldots x_{p}$, the full regression model can be written as:

$$
\log \left(\frac{P}{1-P}\right)=\operatorname{logit}(P)=\beta_{0}+\beta_{1} X_{1}+\beta_{2} X_{2}+\ldots+\beta_{p} \beta_{p}
$$

with $\beta_{0}$ being the regression constant and $\beta_{1}, \beta_{2} \ldots \beta_{p}$ the regression coefficients. For each unit change in a given explanatory variable, the log of the ratio of the 2 probabilities will increase by the estimated $\beta$-value. The potential relationship between the explanatory and dependent variables was evaluated from the reduction in the likelihood values for a model without any independent variables and a model with the variables included. The likelihood difference follows a chi-square distribution, and a significance test for the chi-square of the final model including all independent variables was used to test for a presence of relationship between the dependent and independent variables.

In order to take into account the autocorrelation in occurrence of swarm cluster groups, we added to the environmental predictors a spatial lag as an additional coefficient. The computation of the lag was based on an upper distance bound of $500 \mathrm{~km}$ derived from the autocorrelation function estimate described in the previous section, and the calculation was done using the 'spdep' package in R (Bivand et al. 2012).

\section{RESULTS}

\section{Principal components analysis}

The PCA analysis identified 3 significant PCs that explained $83.1 \%$ of the variance in the swarm property data (Table 3). The first and second PCs were associated with height, length, packing density and inter-swarm distance, with the first PC most strongly relating to height and length and the second to packing density and inter-swarm distance (Fig. 4, Table 3). The third PC, explaining $20.2 \%$ of the variance, was mostly related to swarm depth. Swarm length and thickness were strongly positively correlated as were packing density and inter-swarm distance.

\section{Clustering analysis}

The output from the $K$-means cluster analysis showed that partition into 4 cluster groups maximized the ratio between inter-swarm and intra-swarm variance, thus being the optimal partitioning according to the Calinski-Harabasz criterion. Group 1 swarms contained the highest number of swarms but sum abundance was low, making up $\sim 1 \%$ of the total swarm sum abundance. Group 4 swarms had similar small length and thickness measures as Group 1 swarms, but Group 4 swarms were positioned deeper and with higher inter-swarm distance (Fig. 5, Table 5). Swarms classified to Groups 2 and 3 differed clearly in all measured morphological traits to the swarms in Groups 1 and 4, and together swarms in Groups 2 and 3 constituted $>96 \%$ of the total sum abundance $(59 \%$ in Group 3 and $37 \%$ in Group 2). Swarms from Group 
3 had by far the highest average packing density among the groups and also the highest inter-swarm distance. Group 2 contained the longest and thickest swarms among the groups.
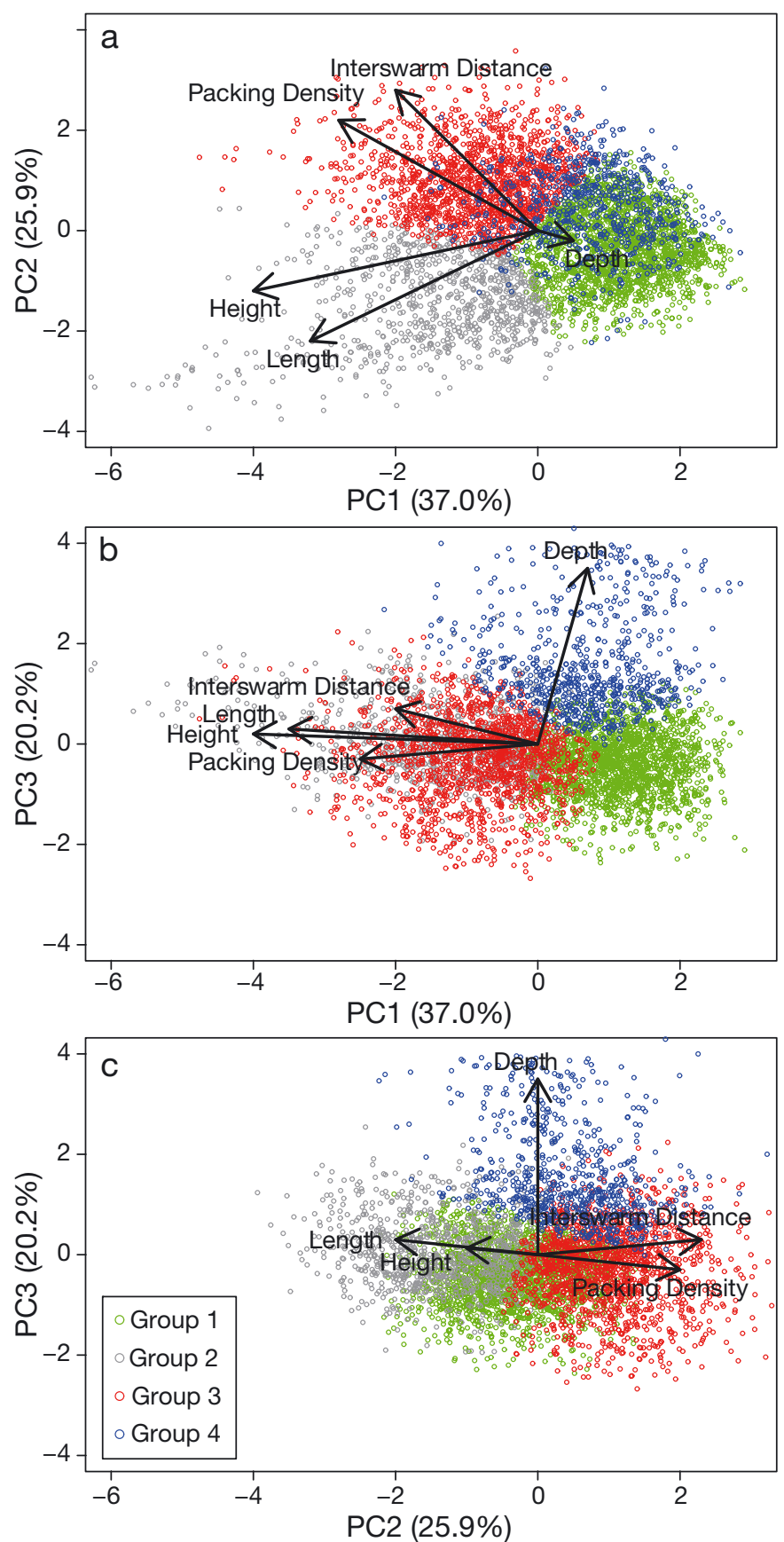

Fig. 4. Principal component (PC) analysis biplot: (a) PC1 vs. PC2, (b) PC1 vs. PC3, (c) PC2 vs. PC3. Numbers in () = percent of total variation explained by each PC. $0,0,0,0=$ detected swarms, colors indicate the 4 identified cluster groups. The direction and length of the arrows mark the direction and rate of steepest increase of the given variable. PC1, PC2 and PC3 had significant explanatory power and their scores were used in the clustering analysis
The test of robustness based on 3 replicates of 1000 randomly sampled data points from the original sample, indicated that the results from the PCA were robust. In all 3 replicates there were 3 PCs that significantly contributed to explain total variance, and the contributed proportion of variance was within $3 \%$ of the original values. The swarm properties dominating the loadings were also very similar with the same properties dominating the PCs. Also the cluster partitioning was relatively robust with 4 categories providing the maximum criterion value in 2 out of 3 instances. In the third instance the index indicated 2 groups as optimal, and in that case the 2 smallest groups (Group 2 and Group 4) were absorbed by the other groups.

\section{Geographical distribution of swarms}

There was a strong positive spatial autocorrelation in the frequency of occurrence of swarms from all 4 swarm cluster groups (Fig. 6). The overall autocorrelation trends varied a little between swarm groups, for instance Group 3 swarms show a less marked spatial correlation at short distances than swarms from the other groups. For all swarm groups, clumped distribution in occurrence of swarms resulted in an effect of autocorrelation up to 400 to $500 \mathrm{~km}$ from an observation, while observations separated by distances higher than that were probably not affected by autocorrelation. The result was used as a justification for the spatial lag of $500 \mathrm{~km}$ chosen for the logistic regression modelling.

In general, krill swarms were recorded regularly along most of the survey track, but ca. $81 \%$ of the swarms were recorded during the first cruise leg and krill swarms were only to a very limited extent recorded north of the South Antarctic Circumpolar Current Front (Fig. 7a). Swarms were also absent between ca. $58^{\circ} \mathrm{S}$ and $55^{\circ} \mathrm{S}$ of the southbound transect line of the second cruise leg along $15^{\circ} \mathrm{E}$ (Fig. $7 \mathrm{a}$ ), an area associated with high salinity values (Fig. 7c). The patchiness in swarm distribution differed between areas (Fig. 7a). Particularly patchy distribution was found along the $0^{\circ}$ meridian south of Bouvetøya, an area associated with abrupt changes in salinity and relatively high current speed related to the South Boundary Front (Fig. $7 \mathrm{c}, \mathrm{d}$ ). The patchiness in swarm distribution also differed between swarm cluster groups as would be expected since the groups differed markedly in inter-swarm distance. Swarms in Group 1 were most patchily distributed with a maximum of 75 swarms recorded during $1 \mathrm{~km}$. 

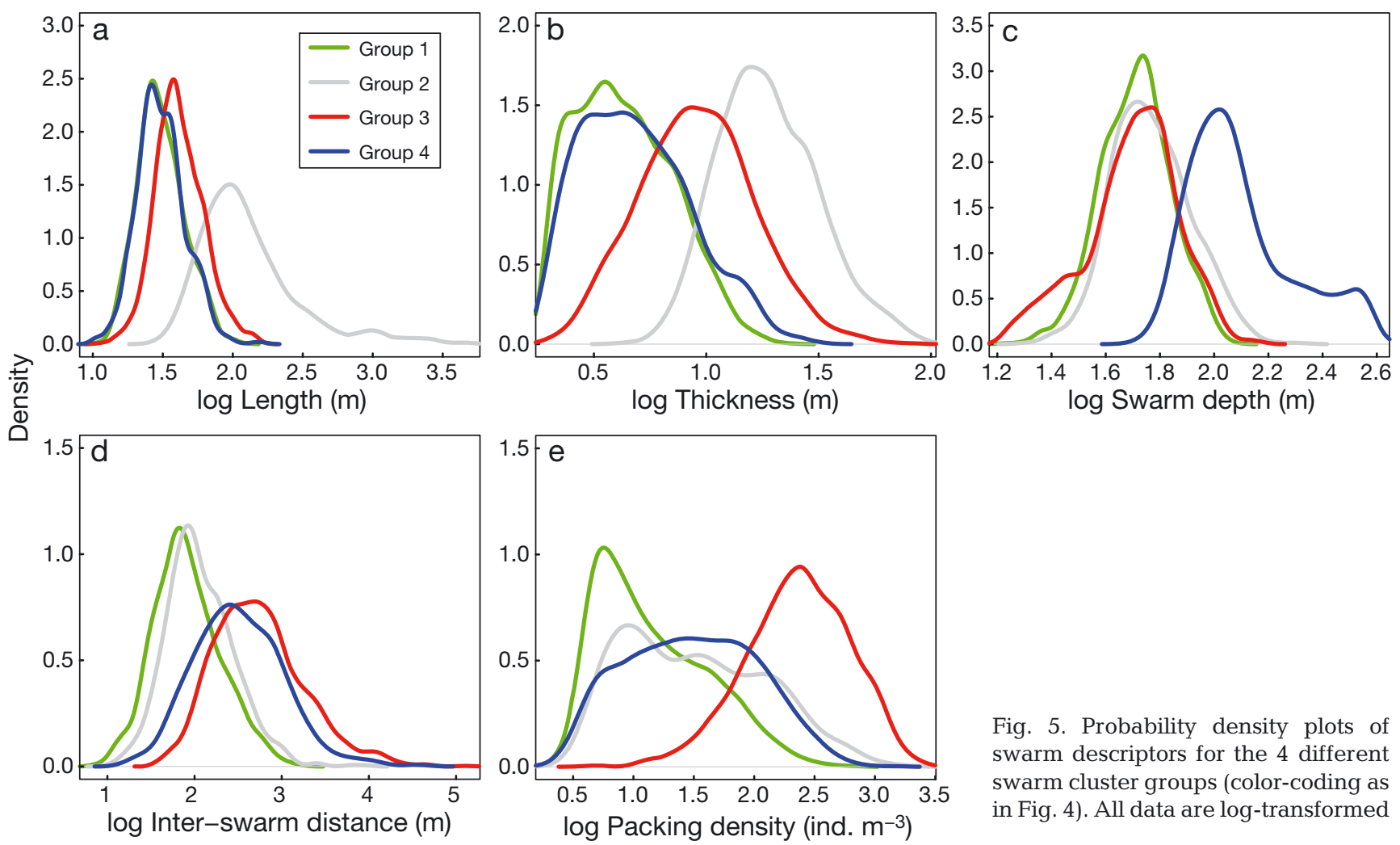

Fig. 5. Probability density plots of swarm descriptors for the 4 different swarm cluster groups (color-coding as in Fig. 4). All data are log-transformed

Swarms from Groups 3 and 4 had a more uniform distribution, and in particular Group 3 swarms had a widespread distribution, with significant occurrences in areas where swarms from other groups were absent. In particular during the second cruise leg Group 3 swarms predominated. Swarms belonging to Group 2 on the other hand were almost absent during the second cruise leg. The swarm recorded closest to shore in the west was $400 \mathrm{~km}$ off South Georgia and only 3 swarms were recorded in waters of $<1000 \mathrm{~m}$ depth on the Bouvetøya shelf.

\section{Environmental influence}

The results from the binomial logistic regression analysis showed that the presence of Group 3 swarms was best predicted by the model (Table 6). The probability of occurrence of such swarms increased with increasing bottom depth and increasing temperature. The predictions are in accordance with the dominance of Group 3 swarms in the deep basins north of the North Weddel Ridge and between the Astrid Ridge and North Atlantic Indian
Table 5. Comparison of differences in length, height, depth, packing density and inter-swarm distance between swarms from the 4 identified cluster groups. Significant differences in bold. Comparison between groups was done using a Kruskal-Wallis rank sum test followed by a Nemenyi-Damico-WolfeDunn joint ranking test (Hollander \& Wolfe 1999), and distance lag to obtain sample independency was set to $13.43 \mathrm{~km}$, which was maximum estimated variogram range (for swarm length) rendering a total $N$ of 223 (for Groups 1 to $4, \mathrm{n}=27,17,41$, and 138 , respectively)

\begin{tabular}{|lrrrrr|}
\hline $\begin{array}{l}\text { Group } \\
\text { comparison }\end{array}$ & Depth & Length & Thickness & $\begin{array}{r}\text { Inter-swarm } \\
\text { distance }\end{array}$ & $\begin{array}{r}\text { Packing } \\
\text { density }\end{array}$ \\
\hline 2 vs. 1 & 0.2577 & $\mathbf{< . 0 0 0 1}$ & $\mathbf{< 0 . 0 0 0 1}$ & 0.4883 & $\mathbf{0 . 0 0 5 1}$ \\
3 vs. 1 & $\mathbf{0 . 0 2 2 0}$ & $\mathbf{0 . 0 4 8 3}$ & $<\mathbf{0 . 0 0 0 1}$ & $<\mathbf{0 . 0 0 0 1}$ & $\mathbf{< 0 . 0 0 0 1}$ \\
4 vs. 1 & $<\mathbf{0 . 0 0 0 1}$ & 0.8562 & 0.7658 & $<\mathbf{0 . 0 0 0 1}$ & 0.9977 \\
3 vs. 2 & $<\mathbf{0 . 0 0 0 1}$ & 0.8005 & 0.4087 & $<\mathbf{0 . 0 0 0 1}$ & $<\mathbf{0 . 0 0 0 1}$ \\
4 vs. 2 & $<\mathbf{0 . 0 0 0 1}$ & $<\mathbf{0 . 0 0 0 1}$ & $<\mathbf{0 . 0 0 0 1}$ & $\mathbf{0 . 0 0 1 9}$ & $\mathbf{0 . 0 0 9 2}$ \\
4 vs. 3 & $<\mathbf{0 . 0 0 0 1}$ & $\mathbf{0 . 0 2 1 0}$ & $<\mathbf{0 . 0 0 0 1}$ & $<\mathbf{0 . 0 0 0 1}$ & $<\mathbf{0 . 0 0 0 1}$ \\
\hline
\end{tabular}




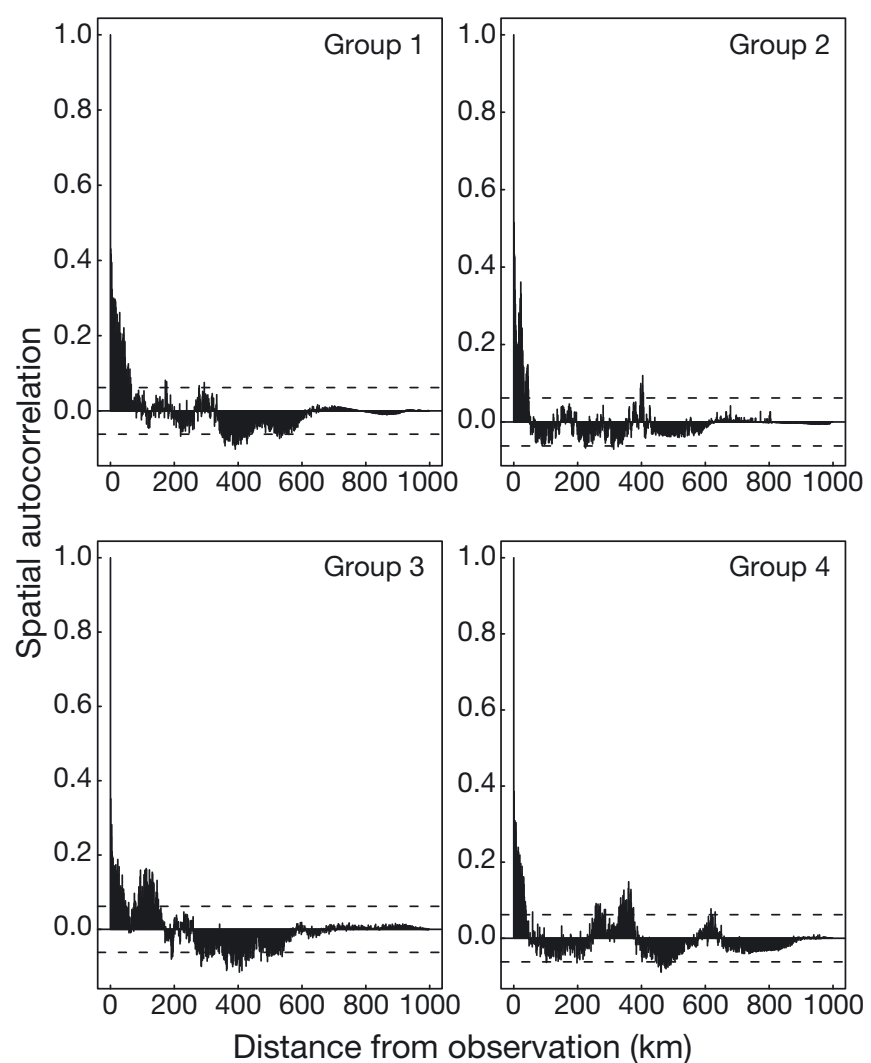

Fig. 6. Estimated autocorrelation function for the 4 swarm cluster groups, derived from swarms detected west of $20^{\circ} \mathrm{W}$ $(\mathrm{N}=1197)$. Estimates are based on the sample covariance and the lag 0 autocorrelation is fixed at 1 . Horizontal dashed lines: $95 \% \mathrm{CI}$

coefficient had a strong effect in the model for all swarm cluster groups.

Swarms from Groups 1 and 2 had similar frequency of occurrence in relation to the environmental variables (Fig. 8). When pooling swarm Groups 1 and 2 and using the binomial regression model to predict occurrence, the predictive power increased markedly as compared to testing the groups separately (Table 6). The probability of occurrence of swarms from Groups 1 and 2 increased with decreasing salinity, temperature and depth and increasing current speed and light level.

\section{DISCUSSION}

\section{Acoustic method}

The present study relies on an acoustic method to describe krill swarm properties including morphological traits and vertical and inter-swarm position across a large geographical area. There are some methodological limitations when surveying at 10 knots speed with conventional echo sounders. Most importantly, the upper 15 to $20 \mathrm{~m}$ of the water column will not be covered due to the hull draft and the acoustic near-field zone, and small entities will not be resolved. The latter was alluded to by Hamner \& Hamner (2000, p. 196) stating '... we saw hundreds of schools of krill, of every conceivable configuration except a solid mass, coursing in different directions, changing depths, coalescing, and separating. A ship passing over such an aggregation probably would have recorded acoustically these complex aggregations as a single solid patch of krill...'. There may, in other words, be behavioural dynamics occurring within the minimum sampling volumes applied in our study, which are lost in the recordings. However, with the large sampling volume and high temporal sampling resolution, acoustics is the only tool by which it is possible to collect swarm property data adequately over such vast latitudinal and longitudinal gradients as was done in this survey.

\section{Swarm properties}

Our results show a relationship between packing density and remoteness to other swarms with swarms far apart from others being more densely packed, as observed in swarms from Group 3. Tarling et al. (2009) argued that increased packing density may be the result of animals decreasing nearest neighbor distance to maintain swarm integrity in reduced visibility. High packing density has also been associated with migration in fish (Pitcher \& Partridge 1979). For fish on the move, the distance to nearest neighbor decreases with swimming speed thereby increasing packing density, resulting in a more homogenous group and reduced risk for individuals of losing contact with the group. Higher packing density will also reduce the visibility to predators and decrease encounter rate with predators due to reduced surface of the aggregation. The cost for an individual of losing the group is high if the group is distant from others, since the probability of reencountering conspecifics will be low. However, it is highly unlikely that krill in swarms have knowledge about the presence of other krill outside their sensing field. A positive correlation between swarm packing density and inter-swarm distance in the absence of concentrating topographical or hydrographical structures must therefore be understood as a result of krill decreasing nearest neighbor distance within a quite extensive range. In the Scotia Sea, Tarling et al. (2009) found 

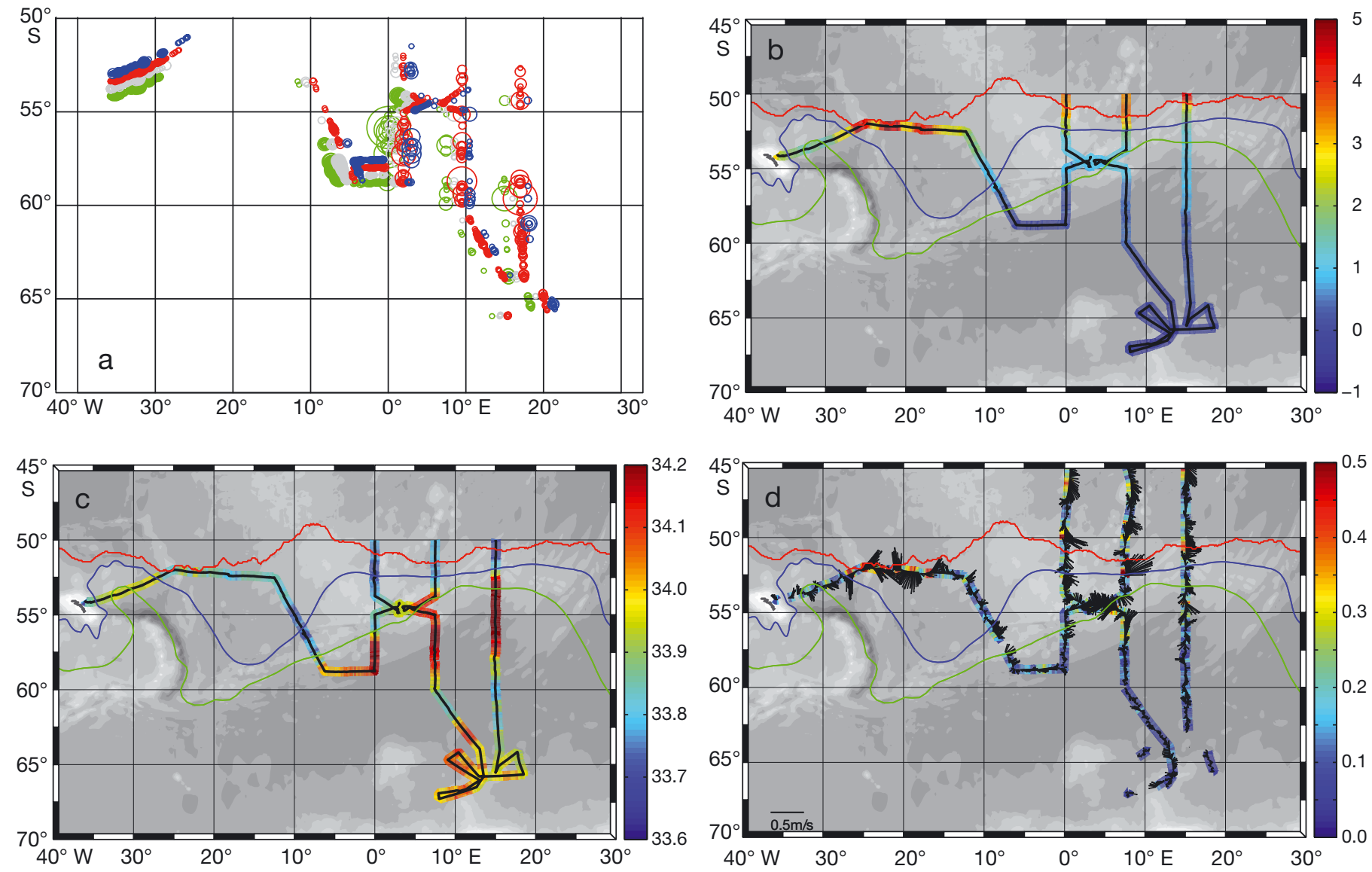

Fig. 7. Geographical distribution of recorded krill Euphausia superba swarms and key environmental variables. (a) Detected swarms with the 4 swarm cluster groups (color-coding as in Fig. 4) identified through $K$-means cluster analysis. The size of the circles corresponds to the square root of the number of identified swarms during a traveled kilometer. For clarity, the original positions for swarms in Groups 2 to 4 have been offset with respect to the neighboring cluster group(s) by $0.4^{\circ}$ latitude for west-eastbound transect parts and $1^{\circ}$ longitude for north-southbound transect parts. (b-d) Distribution of (b) surface temperature $\left({ }^{\circ} \mathrm{C}\right.$ ) and (c) salinity along the transect measured with a thermosalinograph, and (d) current velocity $\left(\mathrm{cm} \mathrm{s}^{-1}\right)$ averaged for 56 to $112 \mathrm{~m}$ depth from acoustic doppler current profiler data. Lines: red $=$ Antarctic Polar Front; blue $=$ South Antarctic Circumpolar Current Front; green $=$ South Boundary Front $($ Orsi et al. 1995). Bathymetry has a $1^{\circ}$ resolution, and comes from the 'm-map' package (R. Pawlowics, rich@ocgy.ubc.ca) in matlab

that the largest and most densely packed swarms were associated with small and immature krill. The relationship between krill length and maturity composition and swarm properties was not investigated in our study, but immature krill made up only a small proportion in our biological samples, suggesting low abundance (see Krafft et al. 2010) while they were dominating in 5 out of 18 stations in Tarling et al. (2009). Such demographical differences may be important in explaining the differences in swarm types between the 2 studies. Despite very similar methods for sampling, identification and measuring of swarm properties, the packing density of the most densely packed swarms (Group 3) in the present study was $>3$ times as high as the most densely packed swarms in Tarling et al. (2009), whereas the largest swarms in the present study had markedly smaller size than the largest swarms in their study. In addition to demographic differences, geographical differences may also have influenced swarm properties, since a higher proportion of the swarms in Tarling et al. (2009) and Klevjer et al. (2010) was on-shelf in coastal waters where the risk for encountering landbased predators is higher than in the high seas areas (Murphy et al. 2007).

\section{Vertical distribution and migration}

Our data showed that there was variation in swimming depth between the different swarm groups. Euphausia superba have extensive flexibility in their vertical migration and distribution, and vertical positioning is typically related to time of the day with 


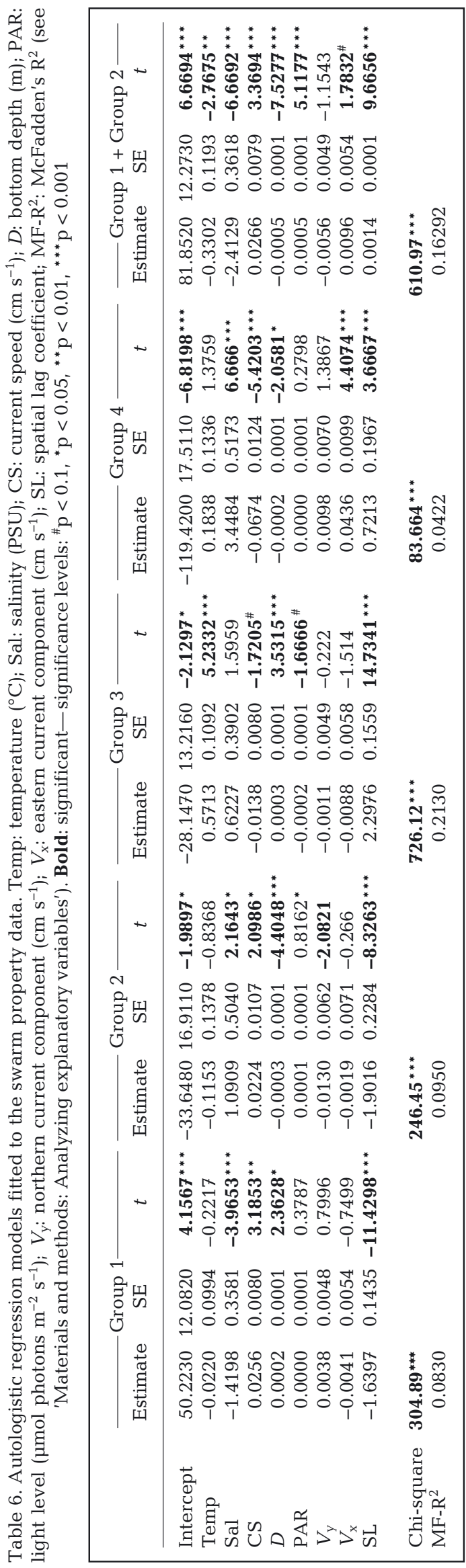

light as the proximate factor and predator protection considered the ultimate factor eliciting vertical migration (Hamner et al. 1983, Hamner \& Hamner 2000, Klevjer et al. 2010). Swarms from Group 4 in our study had a deeper distribution than the others. However, the group was also associated with lower light levels than swarms from swarm Groups 1 and 2, the opposite of what should be expected if the deep distribution was a response to predation risk. Rather, the distribution may be a result of a regionally deeper food distribution and a response to the geographically varying peak depths of phytoplankton (Institute of Marine Research, Norway, unpubl. data).

\section{Geographical swarm distribution and relationship between swarm properties and environmental variables}

The present survey covered extensive latitudinal and longitudinal gradients, mostly areas far offshore. Still, there were few gaps in presence of krill swarms along the survey transect, with the exceptions of the northernmost part of survey leg 1 and a section of the south-heading transect line of survey leg 2. Both of these gap areas were expected to have few krill recordings based on historical data (Atkinson et al. 2008). In the areas containing recordings of krill swarms there was a strong spatial autocorrelation, which diverges from the largely random distribution of krill swarms found for instance by Miller \& Hampton (1989). This divergence presumably confirms that there are significant geographical differences in krill swarm properties (Miller et al. 1993). Even within our study, occurrence of swarms from particular groups showed systematic geographical differences with dominance of Group 3 swarms and absence of Group 2 swarms during the second cruise leg. Miller \& Hampton (1989) suggested that differences in swarm properties would be expected between areas with and without major concentrating topographical structures (e.g. shelves and ridges). Topography also seemed to influence our results, since swarms from Group 3 were associated with deeper waters than the other swarm groups. However, deep waters are not likely to have a concentrating effect on krill swarms, so the high packing density observed for Group 3 swarms is highly likely due to self-propelled locomotion, increased attention and attraction to neighbor individuals. It must be noted that our survey was long-lasting and that seasonal effects therefore may have interfered with the environmental signal. Start of data collection during the first and second legs of 

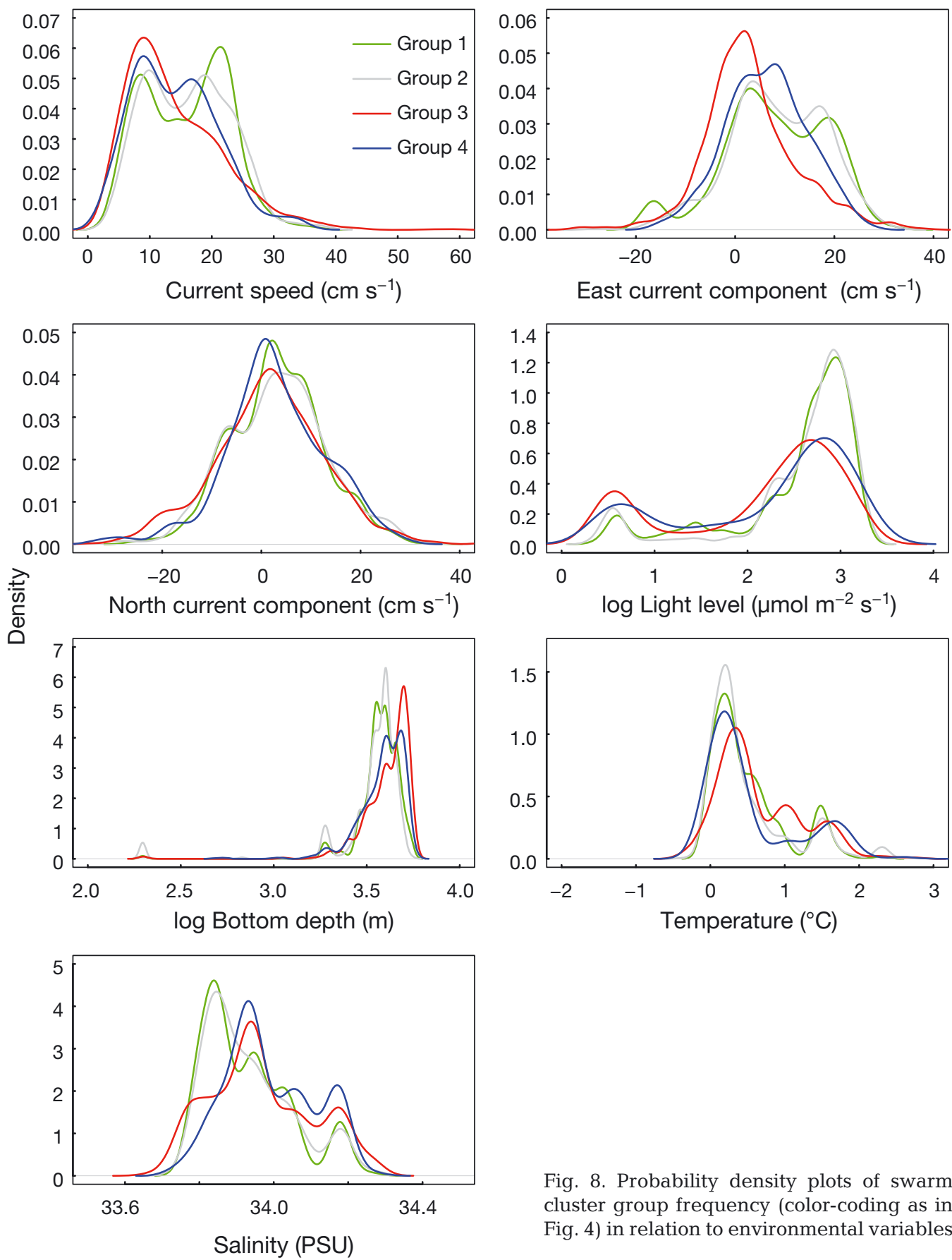

Fig. 8. Probability density plots of swarm cluster group frequency (color-coding as in Fig. 4) in relation to environmental variables

the survey were separated by a month, and krill have a life cycle adapted to seasonal changes with behaviors such as feeding and migration dominating at different times of the year (Nicol 2006), and swarm properties likely affected accordingly. It cannot therefore be excluded that the increased probability of occurrence of Group 3 swarms with increased depth is in reality increased probability of occurrence at late stages in the season, since the late part of the survey was conducted in areas where water depths were generally deeper.

Current drift is important for Euphausia superba transportation and retention (Huntley \& Niiler 1995), and our results indicate that current also influences swarm properties. Increased current speed increased the probability of occurrence of swarms from Groups 1 and 2. These swarms had relatively small interswarm distance and it is conceivable that this prop- 
erty results from joint swarms that have been disrupted by the current. The dominant current direction, on the other hand, seemed to play a negligible role with respect to swarm properties. Whether it influenced the occurrence or not of krill swarms in general was not investigated here, but would be an interesting topic for future work since it might provide new knowledge about the degree to which swarms position themselves according to ambient environment in order to optimize the balance between activities such as feeding, migration and protection from predation. Our results showing that most of the krill were present in swarms of very high packing density and long inter-swarm distance suggest that smallscale locomotion such as swimming to approach neighbors, happening independently of environmental concentrating forces is very important, at least in the high seas.

Acknowledgements. The Royal Norwegian Ministry of Fisheries and Coastal Affairs commissioned and contributed to the AKES expedition. In addition the survey and project were made possible due to contributions by the Institute of Marine Research, The University of Bergen, Norwegian Antarctic Research Expeditions (NARE), The Research Council of Norway, and was also sponsored by Norsk Hydro (StatoilHydro), the Norwegian Petroleum Directorate and ABB Norway. We also extend our gratitude to the crew of the RV 'G. O. Sars' and Elin Hjelset (IMR) for advice regarding the use of ArcGis software.

\section{LITERATURE CITED}

Atkinson A, Siegel V, Pakhomov EA, Rothery P and others (2008) Oceanic circumpolar habitats of Antarctic krill. Mar Ecol Prog Ser 362:1-23

Bivand R, Altman M, Anselin L, Assunção R and others (2012) Spatial dependence: weighting schemes, statistics and models. R package version 0.5-46. http://CRAN.Rproject.org/package $=$ spdep $/$

Brierley AS, Cox MJ (2010) Shapes of krill swarms and fish schools emerge as aggregation members avoid predators and access oxygen. Curr Biol 20:1758-1762

- Calinski T, Harabasz J (1974) A dendrite method for cluster analysis. Commun Stat 3:1-27

Calise L, Skaret G (2011) Sensitivity investigation of the SDWBA Antarctic krill Target Strength Model to fatness, material contrasts and orientation. CCAMLR Sci 18: 97-122

CCAMLR (2010) Report of the fifth meeting of the subgroup on acoustic survey and analysis methods. SC-CCAMLRXXIX/6. CCAMLR, Hobart. Available at www.ccamlr. org/en/sc-camlr-xxix/

> Conti SG, Demer DA (2006) Improved parameterization of the SDWBA for estimating krill target strength. ICES J Mar Sci 63:928-935

Cox MJ, Borchers DL, Demer DA, Cutter GR, Brierley AS (2011) Estimating the density of Antarctic krill (Euphau- sia superba) from multi-beam echo-sounder observations using distance sampling methods. Appl Stat 60:301-316

- Cox MJ, Demer DA, Warren JD, Cutter GR, Brierley AS (2009) Multibeam echosounder observations reveal interactions between Antarctic krill and air-breathing predators. Mar Ecol Prog Ser 378:199-209

> Cox MJ, Warren JD, Demer DA, Cutter GR, Brierley AS (2010) Three-dimensional observations of swarms of Antarctic krill (Euphausia superba) made using a multibeam echosounder. Deep-Sea Res II 57:508-518

Croissant Y (2011) Multinomial model version 0.2-2. R package version 2.13.2. http://CRAN.R-project.org/package= mlogit/

> Demer DA, Conti S (2003) Reconciling theoretical versus empirical target strengths of krill: effects of phase variability on the distorted-wave Born approximation. ICES J Mar Sci 60:429-434

$>$ Evans SR, Finnie M, Manica A (2007) Shoaling preferences in decapod crustacea. Anim Behav 74:1691-1696

Foote KG, Knudsen HP, Vestnes G, MacLennan DN, Simmonds EJ (1987) Calibration of acoustic instruments for fish density estimation: a practical guide. ICES Coop Res Rep 144. ICES, Copenhagen

> Foote KG, Everson I, Watkins JL, Bone DG (1990) Target strengths of Antarctic krill (Euphausia superba) at 38 and $120 \mathrm{kHz}$. J Acoust Soc Am 87:16-24

Hair JF, Tatham RL, Anderson RE, Black W (1998) Multivariate data analysis, 5th edn. Prentice Hall, Upper Saddle River, NJ

$>$ Hamner WM, Hamner PP (2000) Behavior of Antarctic krill (Euphausia superba): schooling, foraging, and antipredatory behavior. Can J Fish Aquat Sci 57:192-202

> Hamner WM, Hamner PP, Strand SW, Gilmer RW (1983) Behaviour of Antarctic krill, Euphausia superba: chemoreception, feeding, schooling, and molting. Science 220: 433-435

> Hartigan JA, Wong MA (1979) A K-means clustering algorithm. Appl Stat 28:100-108

Hollander M, Wolfe DA (1999) Nonparametric statistical methods, 2nd edn. John Wiley \& Sons, New York, NY

Huntley ME, Niiler PP (1995) Physical control of population dynamics in the Southern Ocean. ICES J Mar Sci 52: 457-468

Klevjer TA, Tarling GA, Fielding S (2010) Swarm characteristics of Antarctic krill Euphausia superba relative to the proximity of land during summer in the Scotia Sea. Mar Ecol Prog Ser 409:157-170

Korneliussen RJ, Heggelund Y, Eliassen IK, Øye OK, Knutsen T, Dalen J (2009) Combining multibeam-sonar and multifrequency-echosounder data: examples of the analysis and imaging of large euphausiid schools. ICES J Mar Sci 66:991-997

Korneliussen RJ, Ona E, Eliassen I, Heggelund Y and others (2006) The large scale survey system - LSSS. In: Proc 29th Scandinavian Symp Physical Acoustics, 29 Jan01 Feb 2006, Ustaoset, Norway

Krafft BA, Melle W, Knutsen T, Bagøien E, Broms C, Ellertsen B, Siegel V (2010) Distribution and demography of Antarctic krill in the Southeast Atlantic sector of the Southern Ocean during the austral summer 2008. Polar Biol 33:957-968

Lascara CM, Hofmann EE, Ross RM, Quetin LB (1999) Seasonal variability in the distribution of Antarctic krill, Euphausia superba, west of the Antarctic Peninsula. Deep-Sea Res I 46:951-984 
Lawson GL, Wiebe PH, Ashjian CJ, Chu D, Stanton TK (2006) Improved parameterization of Antarctic krill target strength models. J Acoust Soc Am 119:232-242

Lawson GL, Wiebe PH, Stanton TK, Ashjian CJ (2008) Euphausiid distribution along the Western Antarctic Peninsula. Part A. Development of robust multi-frequency acoustic techniques to identify euphausiid aggregations and quantify euphausid size, abundance, and biomass. Deep-Sea Res I 55:412-431

Mauchline J (1980) Measurement of body length of Euphausia superba Dana. BIOMASS Handbook, No 4

McGehee DE, O'Driscoll RL, Martin Traykovski LV (1998) Effects of orientation on acoustic scattering from Antarctic krill at $120 \mathrm{kHz}$. Deep-Sea Res II 45:1273-1294

Miller DGM, Hampton I (1989) Krill aggregation characteristics: spatial distribution patterns from hydroacoustic observations. Polar Biol 10:125-134

Miller DGM, Barange M, Klindt H, Murray AWA, Hampton I, Siegel V (1993) Antarctic krill aggregation characteristics from acoustic observations in the Southwest Atlantic Ocean. Mar Biol 117:171-183

Murphy EJ, Watkins JL, Trathan PN, Reid K and others (2007) Spatial and temporal operation of the Scotia Sea ecosystem: a review of large-scale links in a krill centred food web. Philos Trans R Soc Lond B Biol Sci 362: 113-148

> Nicol S (2006) Krill currents and sea ice: Euphausia superba and its changing environment. BioScience 56:111-120

Norman GR, Streiner DL (2008) Biostatistics: the bare essentials, 3rd edn. People's Medical Publishing House, Beijing

O'Brien DP, Ritz DA (1988) The escape responses of gregarious mysids (Crustacea: Mysidacea): towards a general classification of escape responses in aggregated Crustacea. J Exp Mar Biol Ecol 116:257-272

Orsi AH, Whithworth T III, Nowlin WD (1995) On the meridional extent and fronts of the Antarctic circumpolar current. Deep-Sea Res I 42:641-673

Editorial responsibility: Hans-Heinrich Janssen, Oldendorf/Luhe, Germany
Pitcher TJ, Partridge P (1979) Fish school density and volume. Mar Biol 54:383-394

- Ricketts C, Watkins JL, Priddle J, Morris DJ, Buchholz F (1992) An assessment of the biological and acoustic characteristics of swarms of Antarctic krill. Deep-Sea Res I 39:359-371

> Ritz DA (1994) Social aggregation in pelagic invertebrates. Adv Mar Biol 30:155-216

> Ritz DA (2000) Is social aggregations in aquatic crustaceans a strategy to conserve energy? Can J Fish Aquat Sci 57: $59-67$

Ritz DA, Foster EG, Swadling KM (2001) Benefits of swarming: mysids in larger swarms save energy. J Mar Biol Assoc UK 81:543-544

Siegel V, Kawaguchi S, Ward P, Litvinov F, Sushin V, Loeb V, Watkins J (2004) Krill demography and large-scale distribution in the southwest Atlantic during January/ February 2000. Deep-Sea Res II 51:1253-1273

Sprong I, Schalk PH (1992) Acoustic observations on krill spring-summer migration and patchiness in the northern Weddell Sea. Polar Biol 12:261-268

Tarling GA, Klevjer $\mathrm{T}$, Fielding $\mathrm{S}$, Watkins $\mathrm{J}$ and others (2009) Variability and predictability of Antarctic krill swarm structure. Deep-Sea Res I 56:1994-2012

> Thorpe SE, Murphy EJ, Watkins JL (2007) Circumpolar connections between Antarctic krill (Euphausia superba Dana) populations: investigating the roles of ocean and sea ice transport. Deep-Sea Res I 54:792-810

Venables WN, Ripley BD (2002) Modern applied statistics with S, 4th edn. Springer, Berlin

- Watkins JL, Brierley AS (2002) Verification of the acoustic techniques used to identify Antarctic krill. ICES J Mar Sci 59:1326-1336

Zar JH (1996) Biostatistical analysis. Prentice-Hall, Englewood Cliffs, NJ

Zhou M, Dorland RD (2004) Aggregation and vertical migration behavior of Euphausia superba. Deep-Sea Res II 51: 2119-2137

Submitted: January 6, 2011; Accepted: June 12, 2012

Proofs received from author(s): September 10, 2012 